\title{
Production of Lactic Acid from Kenaf Core Hydrolysate by Rhizopus oryzae FTCC 5215
}

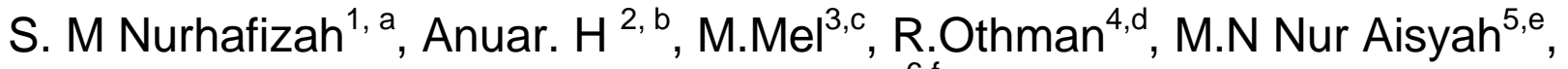 \\ M.N Nur Aimi ${ }^{6, f}$ \\ ${ }^{1,2,5,6}$ Department of Manufacturing and Materials, Faculty of Engineering, International Islamic \\ University Malaysia, P.O Box 10, 50728 Kuala Lumpur, Malaysia \\ ${ }^{3}$ Department of Biotechnology Engineering, Faculty of Engineering, International Islamic University \\ Malaysia, P.O Box 10, 50728 Kuala Lumpur, Malaysia \\ ${ }^{4}$ Department of Landscape and Architecture, Faculty of Architecture and Environmental Design, \\ International Islamic University Malaysia, P.O Box 10, 50728 Kuala Lumpur, Malaysia \\ a nurhafizah.seeni@gmail.com, ${ }^{b}$ hazleen@iium.edu.my, ${ }^{c}$ maizirwan@iium.edu.my, ${ }^{d}$ \\ rashidi@iium.edu.my, ${ }^{\mathrm{e}}$ NurAisyah1910@gmail.com, ${ }^{\dagger}$ aimi_nasir@ymail.com
}

Keywords: Lactic acid, kenaf, fermentation, Rhizopus oryzae

\begin{abstract}
Lactic acid (LA) is commercially produced biologically using food-derived raw materials such as potato and corn. It seems to be less economical since they have to compete with the food sources industries. Thus, kenaf (Hibiscus cannabinus) is found to be the best alternative to substitute the raw material for LA production. In this paper, kenaf core were used as the substrate for production of LA by Rhizopus oryzae FTCC 5215. Since kenaf is one type of lignocellulosic material which is naturally resistant to breakdown to its structural sugars, it will inhibit microorganisms to be accessed through. Thus, hydrolysis process is needed as the aid for the liberation glucose. The highest value of lactic acid produced is $15.2 \mathrm{~g} / \mathrm{L}$ at $25{ }^{\circ} \mathrm{C}$ with speed 200 rpm.
\end{abstract}

\section{Introduction}

Biodegradable polymers are widely used in the mass production applications such as packaging, fibres, and films [1]. The major characteristics that are needed for these applications are biodegradable, non toxic, and safe to the earth or environment. Consequently, the matching monomers to produce polymers should be investigated thoroughly in order to fulfil the above requirements.

The possible monomer in this matter is lactic acid (2-hyrdroxy propionic acid). This is due to the fact that lactic acid is a non toxic, biodegradable, naturally occurring and renewable raw material which is suitable for the applications of food packaging, waste bags, and also agriculture mulch films [1, 2]. Lactic acid is commercially produced by microbial fermentation of the carbohydrates glucose, sucrose, lactose, and starch or maltose, which is derived from feedstock such as beet sugar, whey, and barley malt $[3,4]$. However, these feedstocks are not consistent with market production as the price seems to be gradually increasing parallel to their high demand of supplies. To counteract these feedstock problem, Hibiscus cannabinus.L or well known as kenaf, is chosen.

Kenaf is actively cultivated since it grows faster with height reaches up from 8 to 20 feet. It is being developed as a non wood fibre crop, which contains long soft bast fibres, contributing 30 to $40 \%$ of the dry weight of the stem. The central core of the stem contains a weakly disbursed pith cells surrounded by a thick cylinder of short woody fibres. Other supporting characteristics of kenaf are, the low cost of its productions, and the convenient availability of this sources [5]. Therefore, kenaf is chosen as the newly developed source to generate lactic acid by means of fermentation process in order to produced biodegradable polymers

The aim of this study is to introduce kenaf core as the new substitute from other natural resources in producing lactic acid via fermentation process, with the aid of Rhizopus oryzae FTCC 5215. 


\section{Experimental Methods}

\section{Sample Preparation}

Kenaf core was supplied by Kenaf Natural Fibre Industries Sdn Bhd., Kelantan, Malaysia. It was sieved to 50 to $99 \mu \mathrm{m}$ in size and about $2 \mathrm{~g}$ of it was then treated with hydrochloric acid $(\mathrm{HCl})$ at $125{ }^{\circ} \mathrm{C}$ for about $30 \mathrm{~min}$ to obtain maximum glucose production in hydrolysis process.

\section{Microorganism and Medium Preparation}

Rhizopus oryzae FTCC 5212 was obtained from MARDI. It was inoculated on potato dextrose agar (PDA) in a temperature of $37{ }^{\circ} \mathrm{C}$ for two days. The medium used in this study is potato dextrose broth (PDB). PDB was then mixed together with hydrolysed glucose and was later examined for their $\mathrm{pH}$ level by adding sodium hyroxide $(\mathrm{NaOH})$ or hydrochloric acid $(\mathrm{HCl})$. The initial $\mathrm{pH}$ that would sustain a successful growth of this genetically modified fungus is at $\mathrm{pH} 5$.

\section{Fermentation of Lactic Acid in Shake Flask}

In this study, the fermentation process was done in the shake flask to check the best condition for the process. The process was started off by scraping the fungus off the Petri dishes and added into the mixture of autoclaved PDB and hydrolyzed glucose. The samples were fermented for three days using incubator shaker and general shaker. The experiment was designed by Two Level Full Factorial using STATISTICA 7 Software. The experimental design consists of 4 runs. An average of 3 replicate for each experiment was chosen in order to obtain a good quality results. With the selections of temperature and agitation variation, the software yielded design as Table 1, for avid reference.

Table 1: Parameters for fermentation process

\begin{tabular}{|c|c|c|}
\hline \multirow{2}{*}{ Factors } & \multicolumn{2}{|c|}{ Levels } \\
\cline { 2 - 3 } & Low $(-1)$ & Medium $(0)$ \\
\hline Temperature $\left({ }^{\circ} \mathrm{C}\right)$ & 25 & 37 \\
\hline Agitation speed $(\mathrm{rpm})$ & 150 & 200 \\
\hline \multicolumn{2}{|c}{$\mathrm{n}=12$ runs }
\end{tabular}

\section{Analysis}

The existence of lactic acid was analyzed using high pressure liquid chromatography (HPLC). The HPLC analysis for lactic acid excreted from the metabolic activities of Rhizopus oryzae were performed on an Agilent model 1200 series comprised of a quaternary pump with auto-sampler injector, micro-degassers, column compartment equipped with thermostat and a diode array detector. The column used was a ZORBAX Eclipse XDB-C18 end capped $5 \mu \mathrm{m}, 4.6 \times 150 \mathrm{~mm}$ reverse phase column (Agilent Technologies, USA). The eluent used was buffer: acetonitrile : phosphate $(1: 99 \mathrm{v} / \mathrm{v})$ and the column separation was allowed at a flow rate of $1.0 \mathrm{~mL} / \mathrm{min}$ for 15 minutes. The temperature of the column was maintained at $25{ }^{\circ} \mathrm{C}$.

\section{Results and Discussion}

All data and analysis for this experiment were recorded and analyzed by plotting some graphs after three days of fermentation in shake flask. Table 2 shows the experimental condition for fermentation process, which yields lactic acid as the response. 
Table 2: Experimental condition for fermentation process

\begin{tabular}{|c|c|c|c|}
\hline Run & $\begin{array}{c}\text { Factor } 1: \\
\text { Temperature }\left({ }^{\circ} \mathrm{C}\right)\end{array}$ & $\begin{array}{c}\text { Factor 2: } \\
\text { Speed }(\mathrm{rpm})\end{array}$ & $\begin{array}{c}\text { Response: } \\
\text { Lactic Acid }(\mathrm{g} / \mathrm{L})\end{array}$ \\
\hline 1 & 25 & 200 & 15.2 \\
\hline 2 & 37 & 200 & 5.79 \\
\hline 3 & 25 & 150 & 3.19 \\
\hline 4 & 37 & 150 & 8.23 \\
\hline
\end{tabular}

$\mathrm{n}=12$ runs

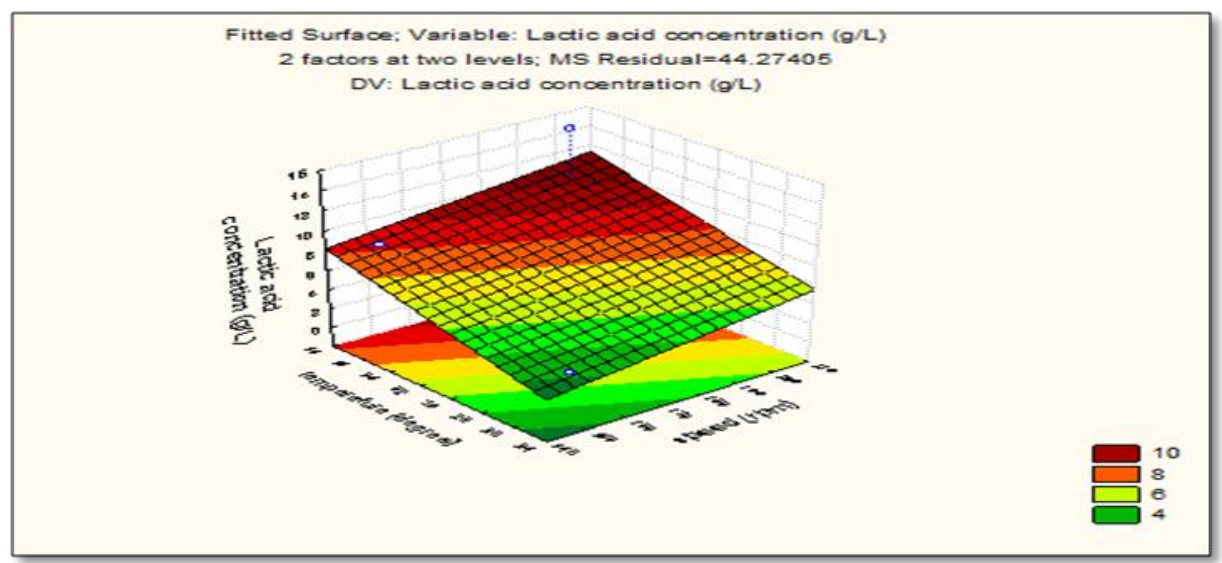

Fig. 1: The relationship between temperature and speed in production of lactic acid

From the Fig. 1, it can be shown that the production of lactic acid was mainly related to the growth of $R$. oryzae FTCC 5215 during fermentation. It is found that the healthy growth and genetically modified of this fungus, yielded high content of lactic acid in varied time and temperature. This can be further elaborated by the fact that the content of glucose in acidic environment ( $\mathrm{pH}$ 5.0) perfected by the ideal temperature and agitation for oxygen, were the appropriate nutrients as well requirement for $R$. oryzae FTCC 5215 to grow. Simultaneously, kenaf core would also be fully utilized by this fungus; therefore, there would be breakdown of the structure of kenaf itself. By mean of this lignocellulosic material, $R$. oryzae FTCC 5215 would have an extra nutrient for them to grow faster in 3 days fermentation.

Upon completion of fermentation process, lactic acid content in all samples was tested. It was investigated that the optimized parameters which yield the highest lactic acid content was at 25 ${ }^{\circ} \mathrm{C}$ at $200 \mathrm{rpm}$ as shown in Fig 1. As illustrated in Fig. 1, with high speed, the containment of oxygen is also increased, thus, the growth of $R$. oryzae FTCC 5212 in fermentation also increased. Not to be forgotten is that, at a suitable temperature, with the combination of sufficient oxygen, the production of lactic acid was at the highest as in Fig. 1. The inference can be made, from the fact that, the small mesh size of raw material facilitates better in fermentation process, which produce higher content of lactic acid [6]. From the result in Table 2, all of the samples seem to yield high lactic acid content. In comparison with Nur Aimi et al. [7], the optimized lactic acid obtained when the parameter is at $25^{\circ} \mathrm{C}$ in $200 \mathrm{rpm}$ with $0.471 \mathrm{~g} / \mathrm{L}$. With the same method, only different in mesh sizes of kenaf core and solvent used, yield a major gap in lactic acid content. Lactic acid content fermented of potato pulp by $R$. oryzae done by Oda [8], somehow only yield $10.3 \mathrm{~g} / \mathrm{L}$. However, the difference was the fermentation process had been done for 6 days in oxygen constrained environment.

\section{Conclusions}

In this paper, it is found that kenaf core has the potential to be raw materials to produce high yield of lactic acid instead of using food derived sources. This could be occurred with the aid of the genetically modified fungus such Rhizopus oryzae FTCC 5212 that has the aptitude to produce high yield of lactic acid after treated. From the result obtained, the optimized condition is at parameter 25 
${ }^{\circ} \mathrm{C}$ and $200 \mathrm{rpm}$. The concentration yielded from this condition is $15.2 \%$. Further study and investigation can be done to enhance the performance and accuracy of lactic acid production such modification of the media and the parameter used in the fermentation process.

\section{References}

[1] Tuominen K, Komiyama A, Sonomoto K, Ishizaki A, Hall SJ, Stanbury R. Two different Pathways for D-xylose metabolism and the effect of xylose concentration on the yield Coefficient of L-lactate in mixed-acid fermentation by the lactic acid bacterium Lactococcus lactis 10-1. Applied Microbiology and Biotechnology Vol 60, No.1-2. (2002). 160-167.

[2] Groot B, Vaughan EE, Luesink E, de Vos WM. Genetics of galactose utilisation via the Leloir pathway in lactic acid bacteria. Lait Vol 78, No.1. (1998). 77-84.

[3] Maas. R.H.W., Bakker .R. R, Mickel.J. L. A., Visser .D., Jong. E.D., Gerrit. E., Ruud.

A.W.Lactic acid production from lime-treated wheat straw by Bacillus coagulans: neutralization of acid by fed-batch addition of alkaline substrate, Appl Microbiol Biotechnol Vol.78, (2008)751-758

[4] Narayanan.N. ,Roychoudhury. P.K.,Srivastava .A. L(+) lactic acid fermentation and its product polymerization. Journal of Biotechnology, Vol.7 No.2. (2004)

[5] I.S. Aji, S.M. Sapuan, E.S. Zainudin, and K.Abdan, Kenaf Fibres as Reinforcement for Polymeric Composite: A Review, International Journal of Mechanical and Material Engineering, vol. 4, no. 3,(2009). 239-248

[6] Johnston, L.J., Robinson, R.A., Clanton, C.J., Goyal, S.M., Ajariyakhajorn, C., \& Heilig, D.M. Homogenization for disposal of dead piglet carcasses. Applied Engineering in Agriculture, Vol 14, No.2. (1998) 183-186.

[7] M.N Nur Aimi, M.K Mohd Adlan, S.M Nurhafizah, H.Anuar, M.Mel, R.Othman. Effect of Rhizopus oryzae fermentation on kenaf-based polylactic acid's Monomer. IIUM Engineering Journal Vol 12, No.4. (2011) 83-87.

[8] Oda Y., Saito K., Yamauchi H., Mori M. Lactic Acid Fermentation of Potato Pulp by the Fungus Rhizopus oryzae, Current Microbiology Vol. 45 (2002), pp. 1-4 DOI: 10.1007/s00284-0010048-y 